\title{
Effects of Urban Growth on Street Networks and Land Use in Mosul, Iraq: A Case Study
}

\author{
Wahda Shuker Al-Hinkawi, Sarah Salh Youssef*, Haneen Ali Abd \\ Department of Architectural Engineering, University of Technology, Baghdad, Iraq
}

Received June 4, 2021; Revised July 12, 2021; Accepted August 22, 2021

\section{Cite This Paper in the following Citation Styles}

(a): [1] Wahda Shuker Al-Hinkawi, Sarah Salh Youssef, Haneen Ali Abd, "Effects of Urban Growth on Street Networks and Land Use in Mosul, Iraq: A Case Study," Civil Engineering and Architecture, Vol. 9, No. 6, pp. 1667-1676, 2021. DOI: 10.13189/cea.2021.090601.

(b): Wahda Shuker Al-Hinkawi, Sarah Salh Youssef, Haneen Ali Abd (2021). Effects of Urban Growth on Street Networks and Land Use in Mosul, Iraq: A Case Study. Civil Engineering and Architecture, 9(6), 1667-1676. DOI: 10.13189/cea.2021.090601.

Copyright $C 2021$ by authors, all rights reserved. Authors agree that this article remains permanently open access under the terms of the Creative Commons Attribution License 4.0 International License

\begin{abstract}
Urban centers grow and expand gradually, and this growth is accompanied by renewal processes for many parts of these centers over time. Traditionally, conditions and needs developed slowly and cities often only changed greatly due to natural disasters or wars. However, with the acceleration of the Industrial Revolution and subsequent important technical transformations in transportation modes, a large, accelerating, and indisputable impact affected historical urban centers, which suffered many morphological changes represented by the intrusive opening of streets to the passage of vehicles with varying degrees of sympathy toward the characteristics of these centers. This research starts from the general hypothesis that street networks affected the changes in old urban centers represented by growth and urbanization and the accompanying change in how parts of this traditional fabric were used. Therefore, we need to have a clear and accurate perception of the change in the characteristics of the spatial organization of the urban and historical centers that resulted from these formal changes. This requires defining and describing the characteristics of this spatial organization before and after these changes occurred. The present research adopts the space syntax method to measure morphological changes and the historic center of Mosul in Iraq is chosen for the practical study due to the city's need for a development strategy that controls expansion and growth when rebuilding the city after the destruction that resulted from the military operations in the war with ISIS.
\end{abstract}

Keywords Urban Growth, Land Use, Space Syntax,
Street Network

\section{Introduction}

Cities, the best examples of complex systems created by humans, comprise many interactive subsystems and are affected by various factors, including governmental land use policies, population growth, and transportation infrastructure. Land use and transportation systems are considered to be the two most essential subsystems that ultimately define the urban form and structure. Meanwhile, urban growth is considered to be one of the most important topics in urban studies [1]. Its main driving forces are represented by population growth and transportation development [2]. The visual characteristics of urban growth are represented by the increase in internal boundaries and traffic volume, complexity of land use, and road traffic patterns [3]. Urban transport has become more complex over time; the purpose of daily commuting, choice of transport, travel time, and cost are some aspects that illustrate this complexity. However, the common factor that directly or indirectly affects all aspects of urban transport and sets the rules for developing urban systems and subsequent urban exchanges is the cost of overcoming those spatial constraints that control the traffic activities in a city [4]. The expansion of the road network drives local urban growth to a certain degree; however, it may also be the result of urban development. Studying the growth 
pattern of the road network is considered to be a starting point for remote sensing technology and a series of models that enable researchers to examine the urbanization process and relevant social and environmental variables in an area [5]. Although the events and activities in a space are essential for the entire city, the intensity of the movement of people and cars on the streets of these cities may be a good indicator of vitality and livability, as high-intensity movements that violate the traditional socio-spatial logic may harm the physical and social environment of cities [6]. Because of inadequate communication channels and cooperation, urban land use and transportation experts have been working separately for many years. Combining urban land use with transportation planning remains unresolved [7]. Owing to the need to address those gaps, urban growth models must consider land use simulations, road network expansion, and their interactions because they ultimately define the urban structure, with the growth in transportation networks significantly affecting urban dynamics. At the same time, urban increase models help explain the mechanisms of urban development, examine modern-day city theories (precisely the dynamic relationships among land use and the street network), and offer planning support for managing the urban growth scenarios [8]. Thus, the objective of this study is to recognize urban growth/city sprawl by modeling and simulating land use change and the growth of the street network. To test the hypothesis that the street network impacts changes in urban areas represented by urban growth and expansion and the accompanying change in land use patterns, we build a model of road networks - as an essential component of the urban growth model - by integrating the available knowledge about the proposed area using space syntax theory with methods in the depth map program. Our aim is to enhance the analysis of the urban road network as an axial map and identify the state of the road network in the old city of Mosul. This city's history starts from its time as an Assyrian camp and encompasses its rise to become an Islamic capital. We investigate every culture that affected the fabric of the city as well as its style and primary traits influencing land use and the distribution of growth. This research develops a multi-step theoretical framework that includes the indicators of urban growth and relationships to the road network and land use. The remainder of the paper is organized as follows. The second section is based on a review of previous studies that have addressed the main research themes. In the third section, Materials and Methods, we explain the processes of collecting data and studying the road network and land uses in the center of Mosul. We also analyze its spatial properties using the depth map. The fourth section discusses the results of the space syntax analysis of the historic city center. Finally, the fifth section presents the research's conclusions

\section{Literature Review}

\subsection{Urban Land Use and Urban Road Transport Networks}

Cities consist of many interactive subsystems. However, when thinking about modifications to urban morphology in the long term, land use and transportation systems are the two most important subsystems and are assumed to change differently over time [2]. Land use improvement patterns (additionally called the urban form, the built environment, network design, spatial improvement, and urban geography) discuss the human use of the city, which incorporates the location, type, and design of infrastructure, including the characteristics of roads and buildings. Land use is considered because it is a visible dimension for a selected area through various human activities (e.g., residential, commercial, and industrial activities). The forms of land use and street network are considered as a part of the transportation system; similarly, the mode of transportation can play a function in determining land use. The network of major roads is considered to be the principle structure in city areas. Thus, roads occupy a large part of a city and establish links with different places, collectively producing the final image of the city. Land use patterns rely on economic, social, and demographic elements and those in any city reflect the population's needs and types of employment. Transportation performs multiple functions in land use by ensuring easy access for people to distinct places and destinations. There are usually excessive interactions among transportation activities and plans to apply to land [8]. Transport directly affects urban development and the spatial distribution of opportunities in various methods such as services, families, and employment [7]. Land use and the transportation network are closely related and, in theory, this is based on the so-called transportation and land use feedback loop shown in Figure (1). Some interactions are straightforward or relatively quick, while others take longer. The system is also dynamic, which means that the left and right sides must be displayed simultaneously. This study aims to verify whether the evolution and size of land use can be explained by the evolution of the network of transportation infrastructure [9]. 


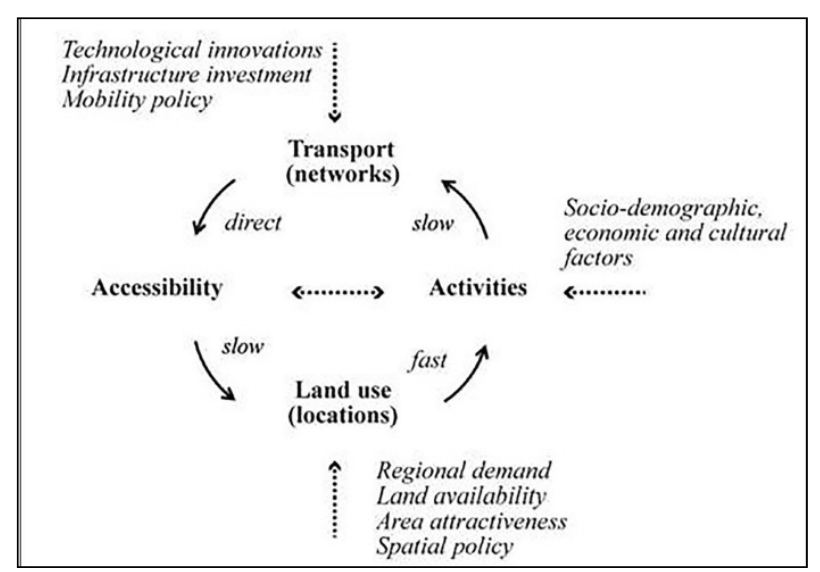

Figure 1. Transportation Infrastructure Network (TIN) and land use (LU) feedback cycle [7].

\subsection{Urban Growth}

Urban growth, urbanization, and urban sprawl are often used synonymously, even though they may differ conceptually. Urban increase is the growth in a city's land cover. Urbanization is a viable strategy for urban increase. Urban increase in line with city or unplanned improvement is known as urban sprawl. Urban sprawl commonly has negative connotations because of the generation or intensification of complicated city problems related to land, water, and air pollution, with negative consequences for human health [5]. Cities allow us to work, create, and enjoy and express ourselves together while sharing urban spaces. Cities succeed when they can organize connectivity and interact. However, purely urban elements such as the composition of the city, presence of urban spaces suitable for interaction, and dynamism of the city center also have an effect. One urban aspect that has received the most scholarly attention is the physical expansion of cities accompanied by a significant loss of density, known in the international literature as urban sprawl $[10,11]$. Studies dealing with urban growth are usually isolated from one another. Economic explanations of urban growth tend to favor rural to urban migration, which is the main driving force behind urbanization, while demographic explanations see urban growth as resulting from natural population growth. In developed countries, population migration is the basis of urban transformation, while natural population growth is the main component in developing countries [12]. Both population growth and migration necessitate a vertical or horizontal extension of the city's structure to meet this growth demand, as shown by the development of the road network and land use to accommodate such growth.

\subsection{Street Network and Its Classification}

With increasing urbanization and the importance of urban studies that explore the environmental, economic, demographic, and social dimensions of cities, street networks have become a major target of scientific and global attention over the past 50 years, where street networks support a wide range of urban operations. The street can be designed as a linear element that provides a path for movement from one end to the other. In urban studies, the role of streets is viewed more comprehensively, where the street is not just a linear channel, but may also be a content of urban life, a reflection, an expression of civil society, and a cultural interface. Thus, the street is a place of human behavior. As people's social and economic interactions are important characteristics, street systems have distinctive features that must be considered to properly understand them as networks [13]. The formation of city street networks and circulation patterns of people and goods underlie urban accessibility. Differences in street networks around the world are based on architecture, topology, cultures, political systems, eras of urbanization, technology, design models, climates, and geography. These networks organize the physical urban space and influence the ability to traverse it through various modes of transport [14]. Hence, the road network is the backbone of urban space development and construction by supporting the flow of people and vehicles as the primary channel; in addition, it plays a fundamental role in urban economic and social development [15]. Street network studies investigate network architecture, connectivity, centralization, hierarchy, classification, and evolution [13]. The street pattern is divided into several elements, including movement, structure, street appearance, location, and display quality. The pattern of movement in street permeability is related to the quality of conduction and its connections [16]. Brindle suggested two main types of street network structures, namely lattice networks and tree networks, which are characterized by the degree of road connectivity [17]. Others distinguish four street patterns. These types are extracted from different urban analyses showing the different phases of a city's growth. Type (a) is a typical pattern that can be observed in many traditional and historical cities, especially walled cities. It is characterized by "the angle of the tracks, directed in various directions, generating a primitive radial, where this pattern is located in the heart of a settlement. Primitive radial, type (b), is a typical street layout pattern arising for newly established expansion or settlement purposes; it is characterized by quadruple vertical junctions naturally leading to bidirectional, with the inclusion of a wider grid shape. Type (c) refers to the most common pattern seen across a city, but mostly runs along an arterial road, whether it forms the central drive of a village, an entire settlement, or a suburban extension along a radial road. Finally, type (d) stands for the modern hierarchical pattern of the street network including curvilinear layouts, distributive roads, and the formation of ring or branching patterns [16], Figure (2). 


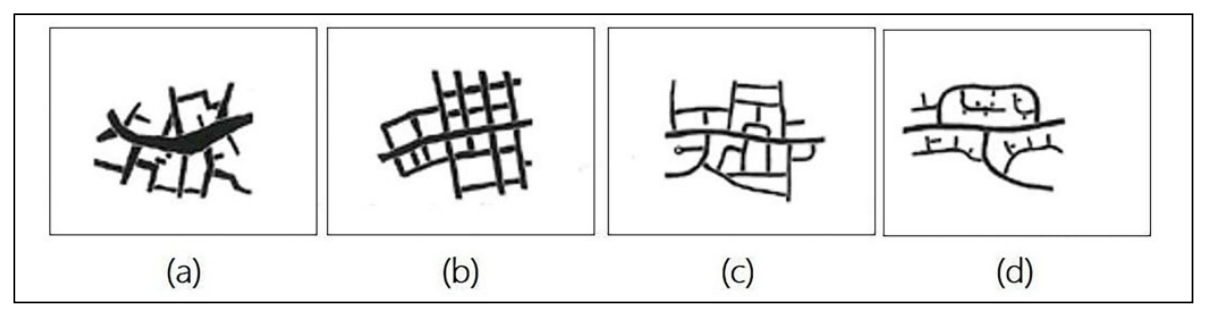

Figure 2. Examples of street patterns ABCD (a) Irregular, (b) Regular, (c) Mixture of regularity and irregularity, (d) Loop roads. [16]

Thus, street patterns can reveal many of the essential features of a city; therefore, they are paramount to city planners and policymakers, as street networks are a complex outcome of city development, which in turn shapes the pattern of future urban development. In the real world, different cities show distinct street patterns due to their histories, geographic surroundings, social and cultural environments, economic conditions, and more.

\section{Methodology}

This research adopts the spatial analysis methodology (space syntax) to measure the morphological characteristics of the fabric represented by the street network and its spatial relationships. It then analyzes its impact on the transformation and expansion of land use in the historic city center of Mosul.

\subsection{Spatial Configuration in Space Syntax Theory}

Space syntax theory is a methodology used to describe the spatial configuration of cities and social logic of space [18]. The theory espouses the idea that the urban structure or spatial formation has a great influence on humans' social activities. The city generally consists of several integrated components. A "physical city" is composed of the physical components such as the buildings and spaces around them, while the "functional city" describes how humans interact with the physical city [19]. Space syntax theory surveys the connections of physical areas using a plan of an urban environment. When analyzing spatial connections, the relationship between spaces can vary according to how they enclose, divide, interfere, and intersect to form a different spatial network [2]. In spatial analysis theory, while the network of spaces presented in urban environment planning appears in all the methods in which spatial units can be associated with every other, syntax represents the network state that describes the relationships among comparable spatial components. Spatial analysis assumes that the spatial network of the urban environment can be diagnosed as exclusive formations for analytical purposes. However, those formations arise in reality. All the methods of searching an area may be visible as layers of the spatial construction, coexisting inside the same plan, each with its contribution to readability and function. Thus, spatial planning may be considered as supplying exclusive functional possibilities [20]. What does a city appear like to walk round? Does it have the potential to generate interaction? Can strangers recognize it? All these questions relate to the connection of the space as formal opportunities related to the various aspects of the job.

Thus, planning may be essential to the spatial system in line with the aspects of syntax analysis in space studies. Those structures use methods and strategies primarily based on contemporary technology and mathematics. These strategies permit many levels to mark, analyze, and visualize spatial network configuration to study how these formations relate to individuals and society via their daily movement [21].

\subsection{Case Study: Mosul- Iraq}

Mosul is located in Nineveh province, about $400 \mathrm{~km}$ north of Baghdad. It represents an important historical, civilizational, and urban identity for Nineveh province in particular and Iraq in general. This fabric is usually referred to as the "old city" because the modern city is much larger. Mosul was established as an Assyrian fortress, and Muslims took control of it in $638 \mathrm{AD}$, when the city was redesigned according to Islamic instructions. Mosul's architectural and urban identity has responded to the local climatic, social, and cultural conditions [22]. This research is based on the expansion of the urban form of Mosul before and after 1940 because in 1937 the two main axes started to enter the historical fabric. Hence, the first stage of the morphological analysis depends on the map of the city from 1911-1920, as shown in Figure (3). The second stage is the current period to study morphological information (Figure 7) to understand how the urban shape of Mosul changed before and after the opening of the two roads and modernization and how this opening affected changes in land use and the nature of growth. 


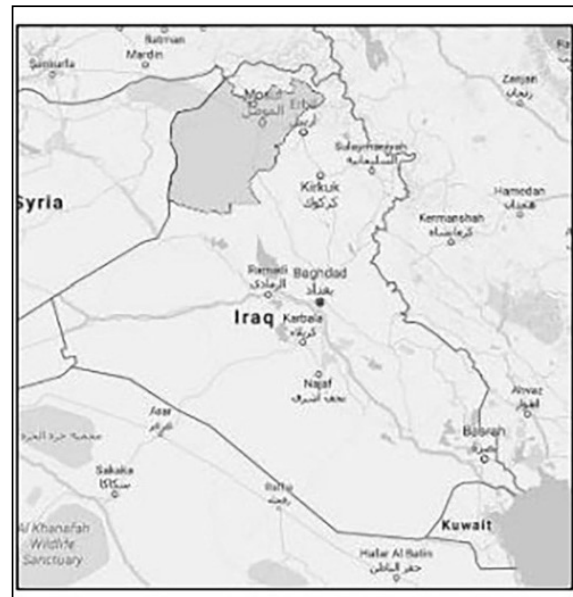

Nineveh Province within Iraq

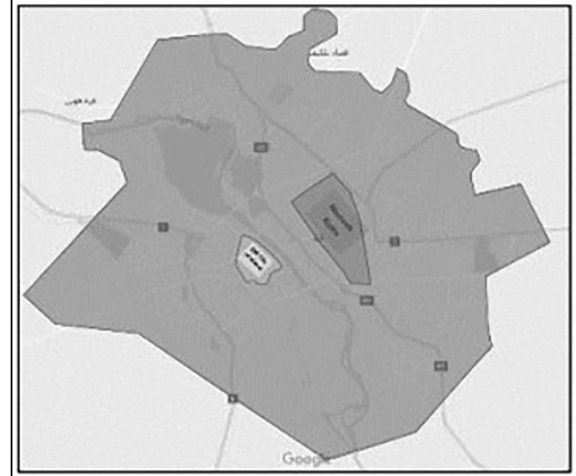

The Old City of Mosul and Historical

Nineveh within the City of Mosul

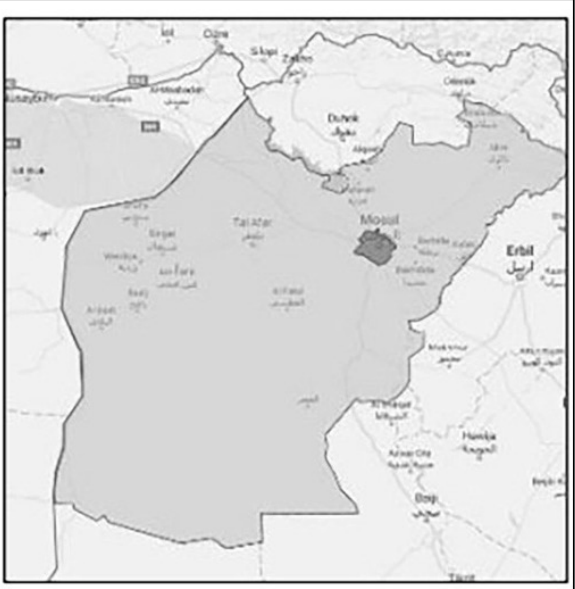

Mosul City within Nineveh Province

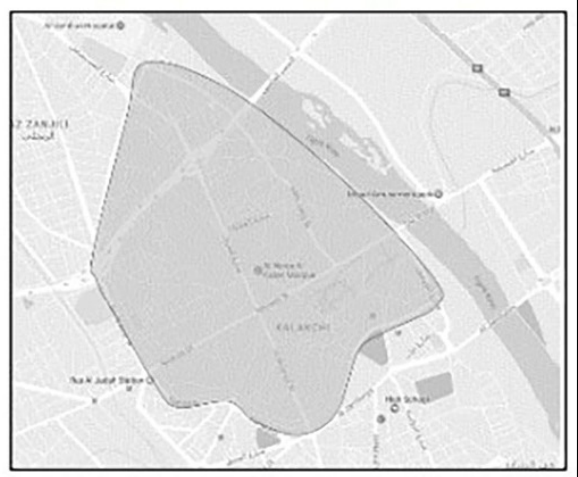

The Old City of Mosul

Figure 3. Map of the Location of Nineveh Province, City of Mosul, Old City of Mosul, and Nineveh Ruins. [23]

\subsection{Analytical Methods}

A descriptive analytical approach is used: Hillier's strategy for morphological analysis with space syntax theory. Mapping the centers of entire city streets to select the major roads by using these models helps improve our understanding of urban morphological development, growth management, and land use simulations to investigate the interaction between land use and the street network. We draw the axial map of the city using a program (depth map) that represents its urban form. A connectivity graph is obtained and access metrics and their indicators can be calculated to understand the relationship between the urban form and choices of city users:

The degree of integration: the degree of integration refers to the interconnectedness or isolation of spaces in relation to the external space. Integration relations include the concept of symmetry. The relative asymmetry scale is generalized by comparing the depth of the system from a certain point with its theoretical depth, and the lowest depth is achieved when all the spaces are connected to the original space. The most profound apace is when all the spaces are arranged in a linear succession away from the original point [19].

The degree of choice: the degree of choice is an indicator of the degree of control that space achieves over the permeability of adjacent spaces, and this represents most choice spaces and the shortest ways that connect the parts of the system with each other or with the external environment, regardless of the number of changes in direction or axial steps organized by it. Thus, the degree of choice is an indicator of the distribution of the movement of the population in the system, which takes the shortest path to move between parts of the city depending on the experience gained as a result of continuous use and learned mental schemes [19].

\section{Results and Discussion}

\subsection{First Morphological Stage}

This stage is characterized by the interconnected urban fabric. Mosul had narrow alleys that varied in width according to its residents and uses. The alleys provided a clear flow of traffic but did not include open urban spaces. 
Therefore, social gatherings were concentrated in religious places, especially mosques. An important aspect of describing the streets of the old city is the direction of traffic, width of the street, and arches. These three factors helped distinguish between old and new streets. The Tigris River, the main source of water for the city's residents, can be seen to have affected the angles and directions of the main alleys of the city. Further, the geographical factor of the terrain directs a few main streets and affects many of the directions of shorter alleys, as shown in Figure (4).

To analyze the street network and accessibility, the axial integration in Figure (4) shows that the streets with the highest integration value are the best at attracting movement, forming the integration core in the city center around the great mosque. The high integration values inside the alleys and the area close to the mosque, which proved the intensity of the activities inside the area, show that the mosque and surrounding area served as a visible attraction for the city's residents.

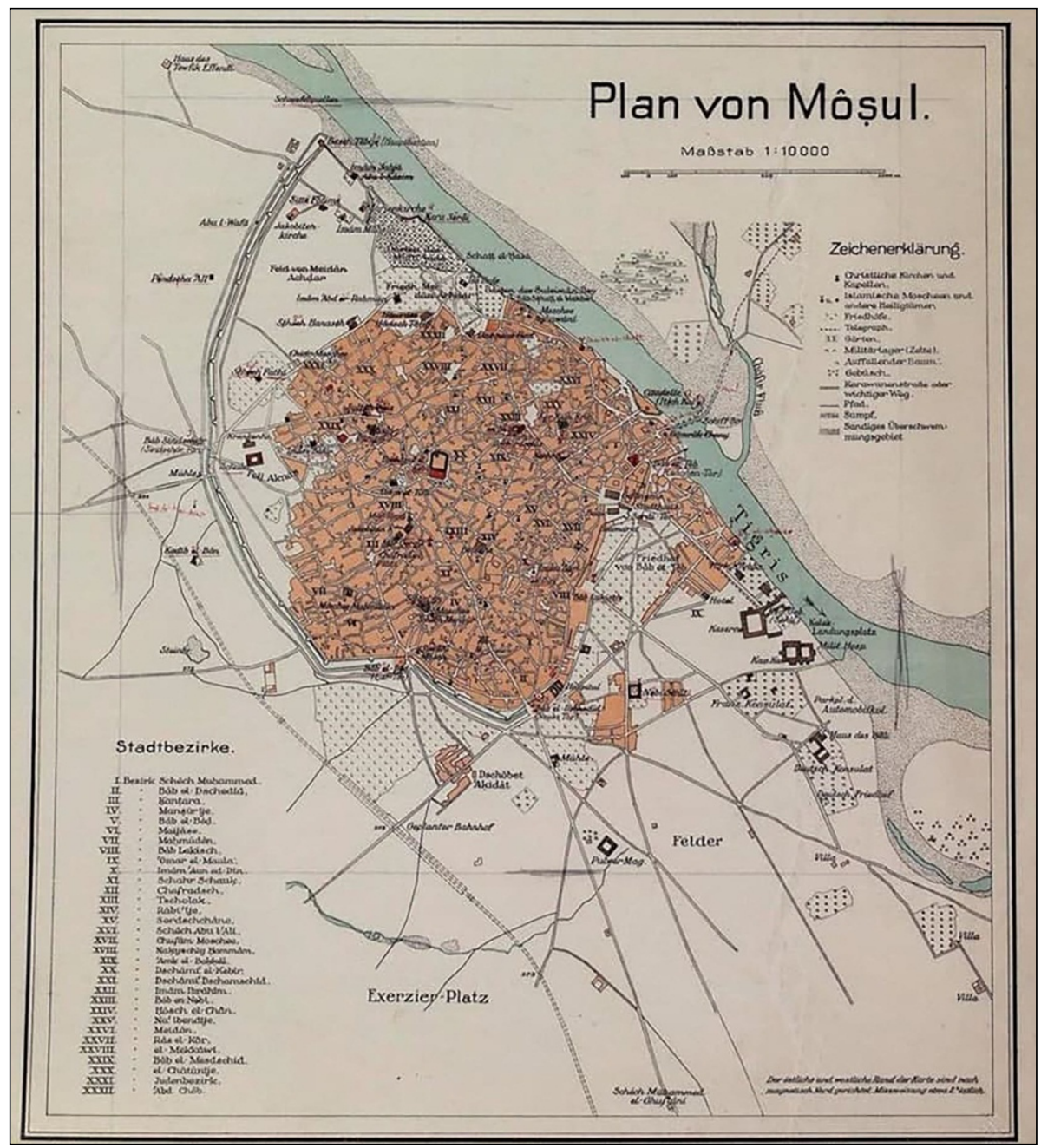

Figure 4. Old Mosul for the period 1911-1920 
The choice map in Figure (5) shows that the best preference alleys have the most movement through them. They have the highest integration values because they are central or connected to the mosque. Hence, movement is focused on the center of the city. The map for 1911-1920 shows that the old city is surrounded by numerous isolated pockets (represented by blue regions), which have the lowest integration values, as they are residential districts that require high privacy (isolation core).

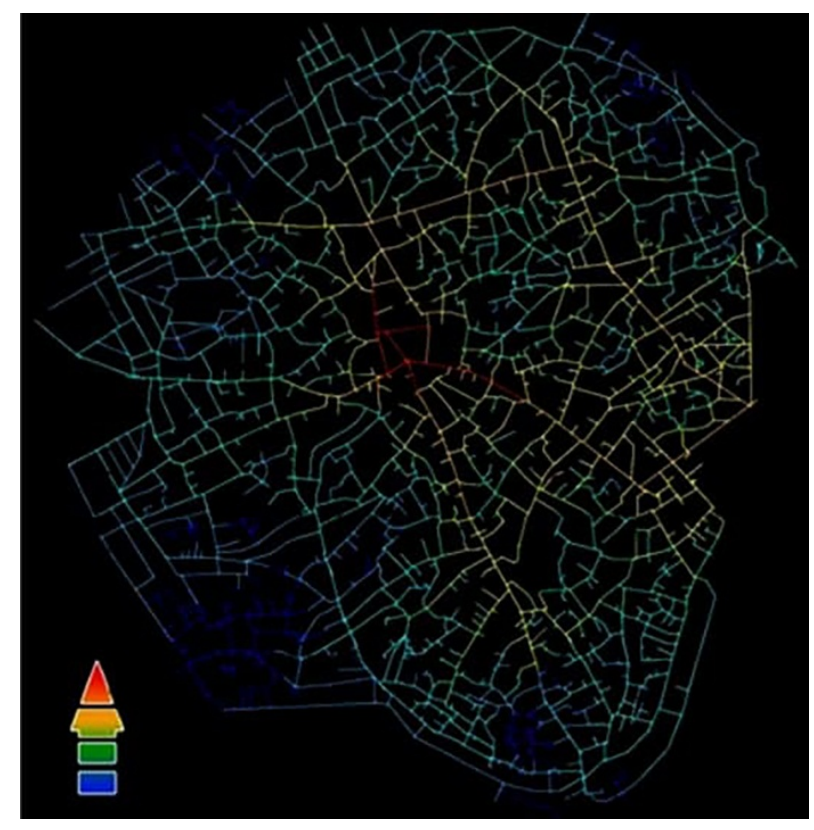

Figure 5. The Axial Integration. (Red color indicates high integration (Integration Core), Blue indicates high Segregation (Segregation Core)

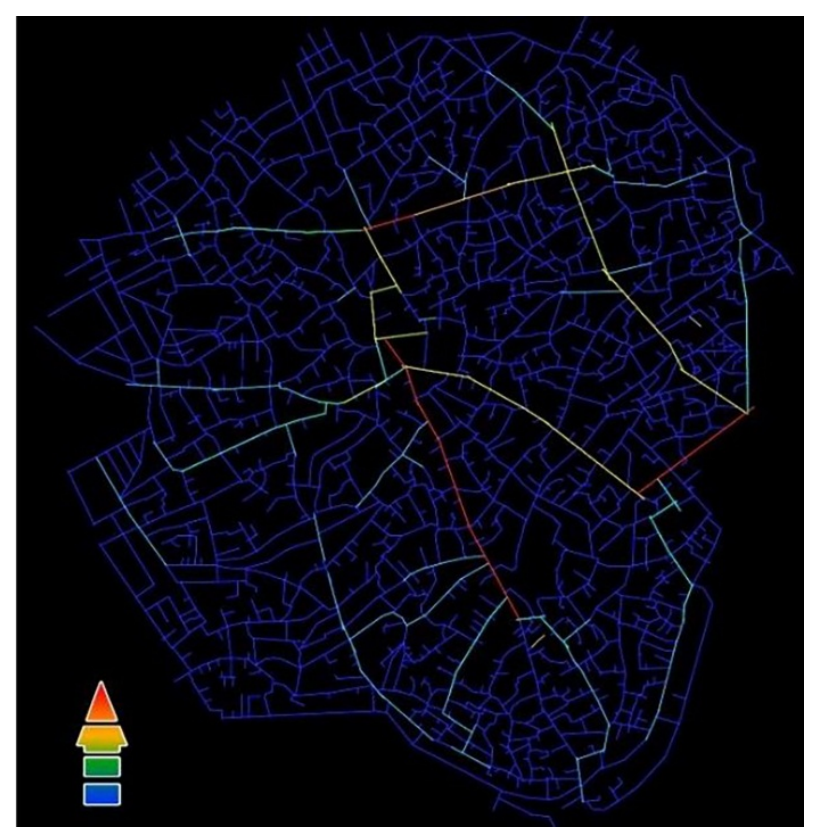

Figure 6. The Axial choice. (Red color indicates high integration (Integration Core), Blue indicates high Segregation (Segregation Core)

Streets with high integration values and axial selection suggest that space is more visible. They tend to go within, or close to, a certain angle. This is characterized by being organically oriented toward the mosque, which confirms the apparent directionality of the fabric in that period regarding land use, including residential use, spread along those alleys. Other uses were limited to the commercial activity in the old city represented by the market and religious buildings that penetrate the fabric of the old area and provide places for social interaction.

\subsection{Second Morphological Stage}

The modernization of Mosul at the beginning of the 20th century included the removal of the inner fortress and opening of Nineveh Street, the construction of the Nineveh Bridge in 1934, the removal of the old bridge, and the opening of King Ghazi Street (Al-Thawra). Although these changes led to limited changes at the urban level, the large-scale demolition and removal works completed to open Corniche Street in 1974 were responsible for changing most of the characteristics of this center, where more than 5.1 hectares of historical buildings were demolished. The Nineveh urban planning unit proposal was implemented in 1992, which included constructing a breakthrough street to change the characteristics of the center. The emergence of vehicles was one of the achievements of the Industrial Revolution in transportation and one of the most prominent technical developments. Its penetration into parts of the urban fabric through wide streets is considered to be an important reason for the loss of the traditional urban fabric. This introduction changed its characteristics, especially since the process of opening streets did not consider the historical importance or architectural value of the buildings because of the straightness and perpendicularity of the intersections required. Based on the changes that occurred in the city, its formation can be divided into two main axes:

1. Nineveh Street: this street passes through the old city from east to west and extends from the Iron Bridge to Ras Al-Jada. It has a length of about $2 \mathrm{~km}$ and is one of the broadest and straightest streets throughout the heart of the city. The opening of Nineveh Street at that time was a new development that the city had never before witnessed. It changed the features of the old city with its narrow alleys, as its long straightness led to the construction of eight residential neighborhoods as well as multi-story commercial buildings in a modern architectural style [25].

2. Al-Farouq Street: this passes through the old city from south to north. Its construction began in the mid-1930s and work was completed in the early 1950s. Its effect on the internal structure of the old district was apparent as it penetrated nine residential neighborhoods. Al-Farouq Street extends for about $2.5 \mathrm{~km}$. It is specialized not only in the sale of goods and merchandise, as in the case of Nineveh Street, but also in plumbing and trade shops [25]. This is shown in Figure (7). 


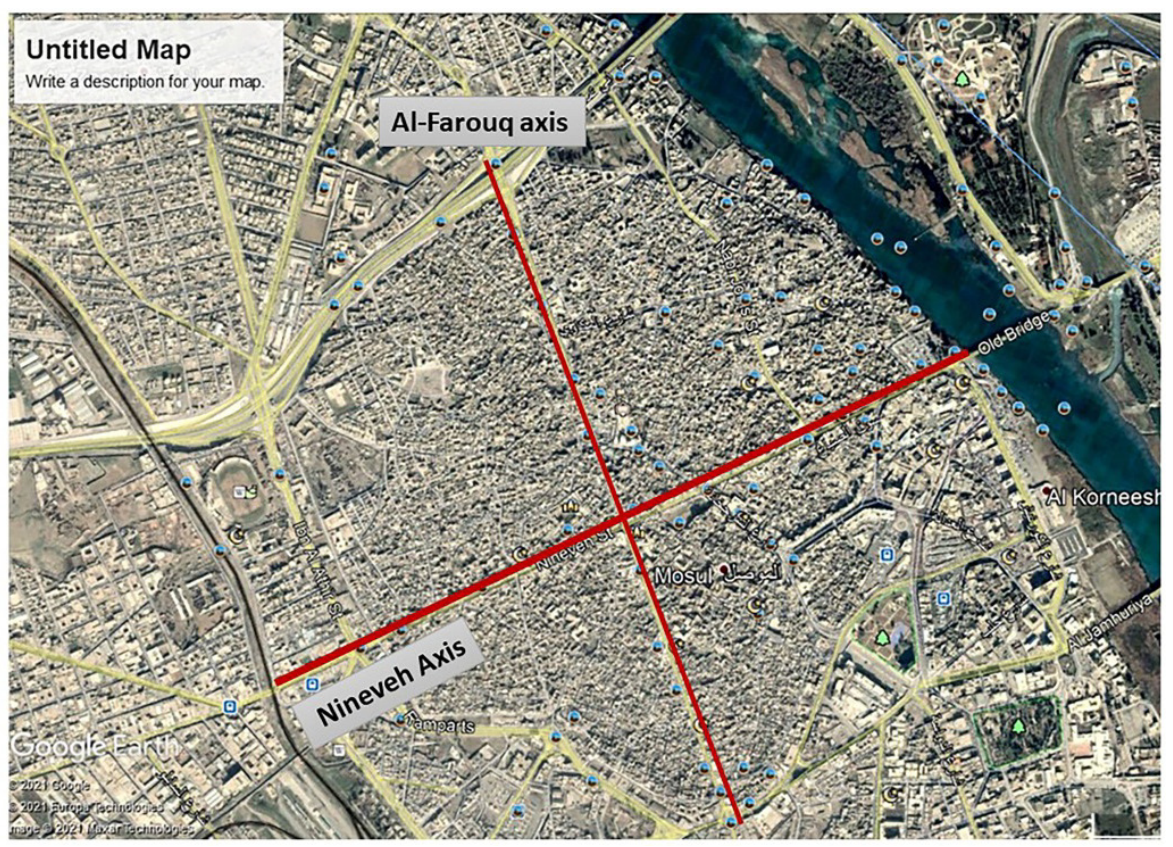

Figure 7. Nineveh Axis and Al-Farouq axis. [26]

Street network analysis and accessibility:

1. Axial integration: high integration values appear on the two main axes (Nineveh axis, Al-Farouq axis) and begin to decline as we move away from the riverbank and the old city. Opening up these wide and straight streets improved ease of access, as shown in Figure (8).

2. Choice values: the highest choice values are also represented in the two main axes, which show the greatest amount of movement. The segregation axes appear near the river, making these streets the main core of movement, as shown in Figure (9).

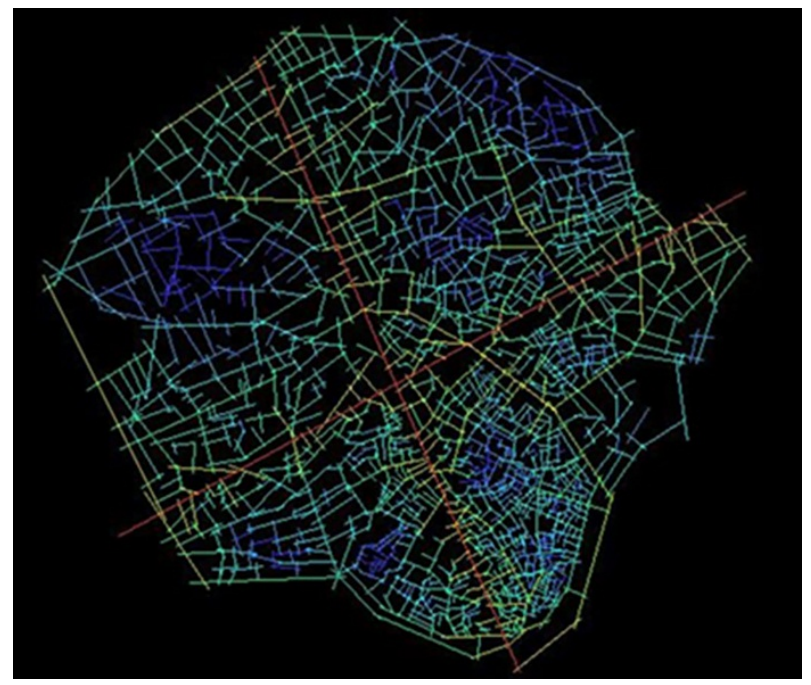

Figure 8. The Axial Integration. (Red colour indicates high integration (Integration Core), Blue indicates high Segregation (Segregation Core)

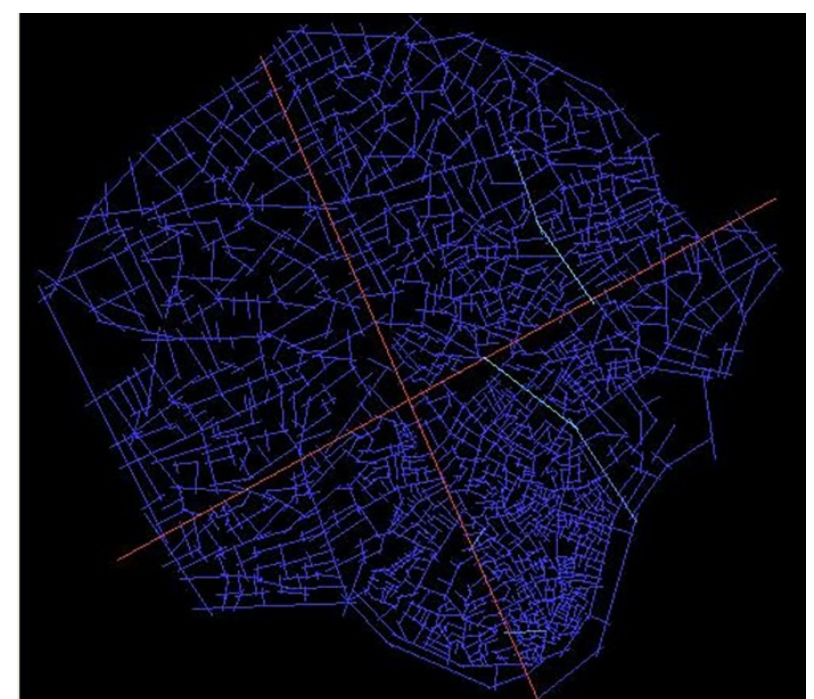

Figure 9. The Axial choice. (Red color indicates high integration (Integration Core), Blue indicates high Segregation (Segregation Core)

The land use diagram of Mosul in Figure (10) shows that the streets with the highest integration and choice values mean that these axes are the most used and seen. They are characterized by their straightness and are considered to be networked axes inserted into the urban fabric of the city, which helps the spread of commercial uses along the length of these axes and thus interaction. These axes link the urban fabrics with each other as well as linking the central axes of the city with the internal alleys of the old area, which helps extend the urban renewal to the heart of the old city. It also reveals the hidden internal parts of the alleys and paths within them and increases the process of attraction and access, leading to commercial land use sprawl in residential areas. 


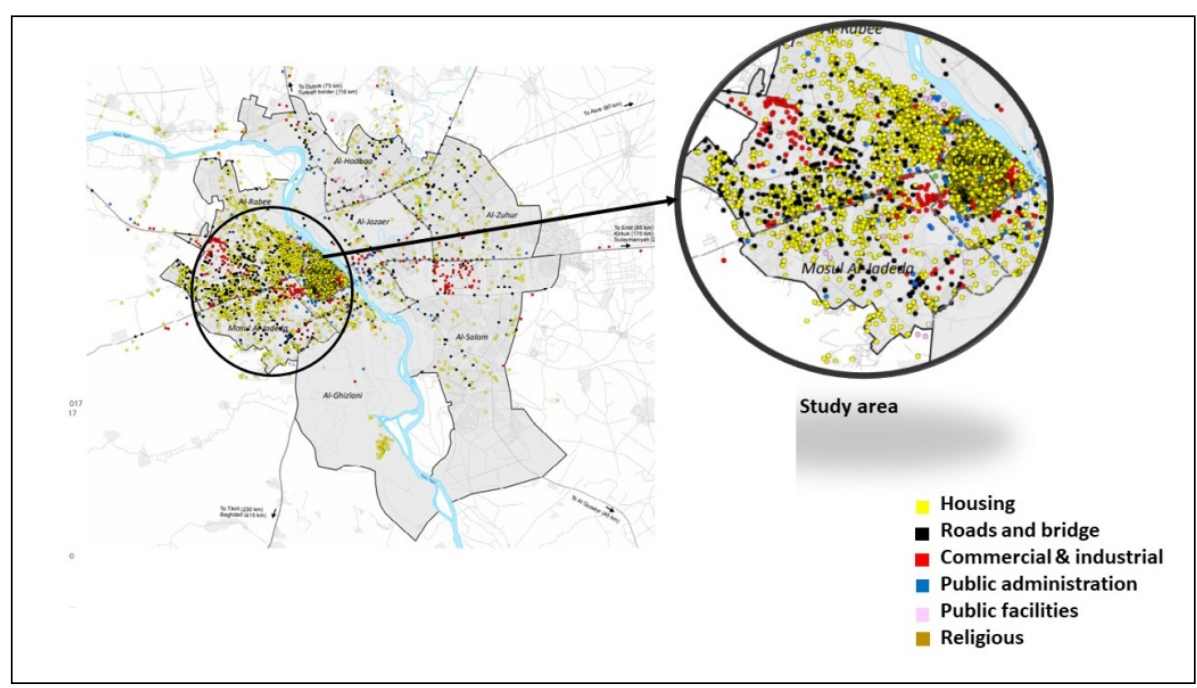

Figure 10. Urban uses a diagram of the current city of Mosul. [27]

\section{Conclusions and Recommendations}

A city is a complex system comprising many interactive subsystems and affected by various factors. Land use and transportation systems are the two essential subsystems that define the urban form and structure in the long term. Meanwhile, urban growth is one of the most important topics in urban studies and the main driving forces are population growth and transportation development.

Based on the results, it is clear that the traditional city with its spatial organization considered the needs of users and the locations of their activities. The relationship between community activities and the spatial organization, led to a livable built environment despite the organic nature

The commercial revitalization linked both sides of the river with the Nineveh Bridge across Nineveh Street. In other words, the changes in the city's physical form led to changes in land use by creating a shared interactive space. The opening of Nineveh Street created a clear axis for commercial activities in contrast to the isolation of internal parts that did not attract commercial use or enhance residents' privacy.

To address this separation and the lack of integration in land uses as well as the clear separation between the two new streets and axes of the organic fabric, the old city of Mosul needs to find plans and alternatives for development. These need to be legal and officially approved by the relevant ministries and apply the concept of "living streets," where streets are created according to social interaction and the promotion of pedestrian safety and accessibility. There is a need to adopt scientific analyses such as the space structure methodology to study the potential effects of any morphological change that results from development projects before initiating it and use them as effective indicators to preserve the characteristics of historical urban centers. This research recommends that further studies develop a suitable street system to assess current street conditions and provide suggestions for improvement.

\section{REFERENCES}

[1] Tan X., Huang B., Batty M., Jing L., "Urban Spatial Organization, Multifractals, and Evolutionary Patterns in Large Cities," Annals of the American Association of Geographers, vol. 18, pp. 1-20, 2020. DOI: $10.1080 / 24694452.2020 .1823203$

[2] María L., Martín C., Analissa I., Betzyand P., Moisés L., "Evaluation of the effects of dispersed urban growth on transportation systems in the eastern area of Panama City," 17th LACCEI International Multi-Conference for Engineering, Education, and Technology: "Industry, Innovation, And Infrastructure for Sustainable Cities and Communities", Jamaica,24-26July2019,pp.1-8,DOI:http:// dx.doi.org/10.18687/LACCEI2019.1.1.406

[3] Arifin, A. E. S., Surya, B., \& Salim, A., "Dampak Urban Sprawl Terhadap Pola Pergerakan Studi Pada Koridor Jalan Letjend. Hertasning Kota Makassar," Urban and Regional Studies Journal, vol.3, no.1, pp.23-31, 2020.DOL: https://doi.org/10.35965/ursj.v3i1.606

[4] Tsiotas, D., Polyzos, S., "The topology of urban road networks and its role to urban mobility," 3rd Conference on Sustainable Urban Mobility, 3rd CSUM 2016, 26 - 27 May 2016, Volos, Greece, vol.24, pp. 482-490. https://doi.org/10.1016/j.trpro.2017.05.087

[5] Viana CM., Oliveira S., Oliveira SC., Rocha J., "Land use/land cover change detection and urban sprawl analysis," in Spatial modeling in GIS and $\mathrm{R}$ for earth and environmental sciences, Elsevier ,2019, pp. 621-651. DOI: https://doi.org/10.1016/B978-0-12-815226-3.00029-6

[6] Bindajam A., Mallick J., "Impact of the spatial configuration of streets networks on urban growth: A case study of Abha City, Saudi Arabia," Sustainability, vol. 12, no. 5, pp. 1-14, 2020. https://doi.org/10.3390/su12051856 
[7] Kasraian D., Maat K., Stead D., van Wee B., "Long-term impacts of transport infrastructure networks on land-use change: an international review of empirical studies. Transport reviews," vol. 36, no. 6, pp. 772-792, 2016. https://doi.org/10.1080/01441647.2016.1168887

[8] Qtiashat D., Makhmreh Z., Taleb HA., Khalaifat A., "Urban land use pattern and road network characteristics using GIS in Al Salt City, Jordan," Modern Applied Science, Vol. 12, no. 4, pp. 128-142, 2018. DOI: 10.5539/mas.v12n4p128

[9] Ahmadzai F., "Analyses and modeling of urban land use and road network interactions using spatial-based disaggregate accessibility to land use," Journal of Urban Management, vol.9, no.3, pp. 298-315, 2020. https://doi.org/10.1016/j.jum.2020.06.003

[10] Rubiera-Morollón F., Garrido-Yserte R., "Recent Literature about Urban Sprawl: A Renewed Relevance of the Phenomenon from the Perspective of Environmental Sustainability," Sustainability, vol,12(16), no., pp. 1-14, 2020. doi:10.3390/su12166551.

[11] G. Shi, J. Shan, L. Ding, P. Ye, Y. Li, and N. Jiang, "Urban road network expansion and its driving variables: a case study of Nanjing City,” Int. J. Environ. Res. Public Health, vol. 16, no. 13, pp. 18-23, 2019.https://doi.org/10.3390/ijerph16132318

[12] K. Farrell, "The rapid urban growth triad: a new conceptual framework for examining the urban transition in developing countries," Sustainability, vol. 9, no. 8, pp.1-19, 2017. https://doi.org/10.3390/su9081407

[13] Marshall S., Gil J., Kropf K., Tomko M., Figueiredo L., "Street network studies: from networks to models and their representations," Networks Spat. Econ., vol. 18, no. 3, pp. 735-749, 2018. https://doi.org/10.1007/s11067-018-9427-9

[14] Boeing G., "Street Network Models and Indicators for Every Urban Area in the World," Geographical Analysis, pp.1-19, 2021. DOI:10.1111/gean.12281

[15] Zhang X., Ren A., Chen L., Zheng X., "Measurement and Spatial Difference Analysis on the Accessibility of Road Networks in Major Cities of China," Sustainability, vol.11, no.15, pp.1-15, 2019. https://doi.org/10.3390/su11154209

[16] Ismail WN., Ja'afar NH., Arabi F., Husini EM., "Character of Traditional Street: An Overview of Physical Components Associated with Building, Landscape and Street Pattern in Royal Town," InIOP Conference Series: Materials Science and Engineering 2018 Sep 1, vol. 401, no. 1, doi:10.1088/1757-899X/401/1/012019

[17] Han B., Sun D., Yu X., Song W., Ding L., "Classification of urban street networks based on tree-like network features," Sustainability, vol.12, no.2, pp.1-13, 2020. https://doi.org/10.3390/su12020628

[18] El-Darwish I. I., "Enhancing outdoor campus design by utilizing space syntax theory for social interaction locations," Ain Shams Engineering Journal, pp.1-7, 2021. https://doi.org/10.1016/j.asej.2021.06.010

[19] Van Nes A., \& Yamu C., "Space Syntax: A method to measure urban space related to social, economic and cognitive factors," In The virtual and the real in planning and urban design, Routledge, 2017, pp. 136-150.

[20] Dawes M. J., Ostwald M. J., \& Lee J. H., "Examining control, centrality and flexibility in Palladio's villa plans using space syntax measurements," Frontiers of Architectural Research, pp.1-16, 2021. https://doi.org/10.1016/j.foar.2021.02.002

[21] van Nes A., Yamu C., "Space Syntax: A method to measure urban space related to social, economic and cognitive factors," In The virtual and the real in planning and urban design, 2017 Oct 12, pp. 136-150, Routledge. DOI: https://doi.org/10.4324/9781315270241

[22] Abdeldayem WS., El-Khouly T., "Investigating the urban structure of newly planned cities in Egypt: The case study of New Cairo city," In Architecture and Urbanism: A Smart Outlook, 2020, pp.401-410. DOI: https://doi.org/10.1007/9 78-3-030-52584-2_28

[23] Yaqub., Lina G., "The Impact of the Baghdad-Berlin Railway on the City of Mosul: Urban Form, Architecture, and Housing," PhD thesis, University of Cincinnati,2019

[24] Shields, S. D., "Mosul before Iraq: Like Bees Making Five-Sided Cells," (SUNY Series in the Social and Economic History of the Middle East.) Albany: State University of New York Press, 2000, pp.19.

[25] Hasan N. A., Al-Hinkawi W. S., \& Alatta A,. "The role of planning urban axes in the sustainability of Iraqi cities Mosul-case study," International Journal of Architecture (IJA), vol.3, no.2, pp. 18-33, 2017.DOI: http://www.iaeme.com/IJA/issues.asp?JType=IJA\&VType $=3 \&$ IType $=2$

[26] https://www.google.com/maps/place/Mosul/@36.3528058, $43.0703329,23183 \mathrm{~m} / \mathrm{data}=! 3 \mathrm{~m} 1 ! 1 \mathrm{e} 3 ! 4 \mathrm{~m} 5 ! 3 \mathrm{~m} 4 ! 1 \mathrm{~s} 0 \times 40079$ 464db1a88b9:0x9745d74edd0f0930!8m2!3d36.3489278!4 d43.157736

[27] https://www.globalsecurity.org/military/world/iraq/maps-o thercities $2 . h t m$ 